\title{
CRITICAL FACTORS OF THE APPLICATION OF NANOTECHNOLOGY IN CONSTRUCTION INDUSTRY BY USING ANP TECHNIQUE UNDER FUZZY INTUITIONISTIC ENVIRONMENT
}

\author{
Shahram SHARIATI ${ }^{\mathrm{a}}$, Masoumeh ABEDI ${ }^{\mathrm{a}}$, Alieh SAEDI ${ }^{\mathrm{b}}$, Abdolreza YAZDANI-CHAMZINI ${ }^{\mathrm{c}}$, \\ Jolanta TAMOŠAITIENE ${ }^{\mathrm{d}}$, Jonas ŠAPARAUSKAS ${ }^{\mathrm{d}}$, Stanislav STUPAK ${ }^{\mathrm{d}}$ \\ a Department of Architecture, Sari branch, Islamic Azad University, Sari, Iran \\ ${ }^{b}$ Imam Khomeini International University, Qazvin, Iran \\ ${ }^{c}$ Young Researchers and Elite Club, South Tehran Branch, Islamic Azad University, Tehran, Iran \\ ${ }^{d}$ Faculty of Civil Engineering, Vilnius Gediminas Technical University, Sauletekio al. 11, LT-10223 Vilnius, \\ Lithuania
}

Received 09 Apr 2017; accepted 24 May 2017

\begin{abstract}
Nanotechnology plays a significant role in construction industry. The construction industry has been employed nanomaterials to improve the performance of construction components and the safety of the structure and to reduce the energy consuming and the cost of maintenance. In other words, nanotechnology has a substantial impact on the construction industry. Therefore, it is necessary to identify and evaluate the critical factors of the application of nanotechnology in construction in order to concentrate on the most critical factors. However, several techniques have been developed to prioritize the evaluation criteria. Analytical network process (ANP) technique, a branch of multi criteria decision making (MCDM) methods, is a powerful tool to rank a limited number of criteria. This technique takes into account both tangible and intangible criteria in the process of formulation of a decision making problem. This method is capable of handling all types of independence and dependence relationships. On the other hand, intuitionistic fuzzy set (IFS) is a well-known technique in considering the inherent uncertainty involved in the process of modelling a decision making problem. In this paper, a new model based on the IFS and ANP technique is proposed to evaluate the critical factors of the application of nanotechnology in the construction industry. The results demonstrate that the proposed model has a high potential for taking into account the uncertainty in the form of a three dimension function, including membership, non-membership, and non-determinacy.
\end{abstract}

Keywords: Intuitionistic fuzzy set (IFS), Analytical network process (ANP), construction industry, nanotechnology.

\section{Introduction}

Nanotechnology has recently become one of the most attractive areas in science and physics. Nanotechnology refers to the manipulation of matter on a molecular and atomic scale with at least one dimension less than 100 nanometers. The nanotechnology includes the understanding of the fundamental technology, biology, chemistry and physics of nanoscale objects. The significance and importance of controlling matter at the nanoscale is that at this scale different laws of physics come into play (Zhu et al. 2004). Nanotechnology leads to a better, smarter, faster, cheaper, and cleaner product. Nanotechnology can affect all materials (GhorshiNezhad et al. 2015): (i) ceramics, (ii) metals, (iii) polymers, (iv) biomaterials, and (v) semiconductors. However, nanotechnology has an enormous impact on production, construction, energy saving, environmental protection, etc.
In the early 1990s, the construction industry was known as a sector with high potential for application of nanotechnology (Bartos 2006). The key importance of nanotechnology in construction is highlighted by Saafi and Romine (2005). The construction industry is identified as one of the top forty industrial sectors influenced by nanotechnology in the near future (Baer et al. 2003).

In the construction industry, several applications have been developed to improve the durability and enhanced performance of construction components, energy efficiency, safety of the buildings, and facilitating the ease of maintenance (Keleş 2009).

The use of nanotechnology materials and applications in the construction industry should be considered not only for enhancing material properties and functions but also in the context of energy conservation. This is a

Corresponding author: Jolanta Tamošaitienè

E-mail: jolanta.tamosaitiene@vgtu.lt 
particularly important prospect since a high percentage of all energy used (e.g. $41 \%$ in the United States) is consumed by commercial buildings and residential houses by applications such as heating, lighting, and air conditioning.

However, the construction industry plays a significant role in the world economy. Based on the statistics issued by Global Construction Perspectives and Oxford Economics (2015), the average global construction growth is $3.9 \%$ per annual to 2030 . This report also shows that only for three countries, China, US, and India (accounting for $57 \%$ of all global growth), the volume of construction output will grow by $85 \%$ to $\$ 15.5$ trillion worldwide by 2030 .

Therefore, it is important to evaluate the critical parameters influencing the application of nanotechnology in construction. This analysis can help decision maker to understand which components require more focus.

However, a number of techniques, including theoretical, analytical, and mathematical, have been developed to evaluate and rank the elements under consideration. Multi criteria decision making (MCDM) methods are well known as powerful and useful tools for solving a complex problem with both quantitative and qualitative criteria that are often in conflict with each other. However, in real world problems, the evaluation criteria are often dependent on each other and the assumption of independence between the criteria is not always accurate. Analytical network process (ANP), a particular branch of the MCDM methods, is a powerful technique in facing with all kinds of relationship, dependency and feedback in the model and draws a systematical figure of the decision making problem (Azimi et al. 2011). The main reasons for using an ANP-based decision analysis approach are (Fouladgar et al. 2012): (1) ANP can measure all tangible and intangible criteria in the model; (2) ANP is a relatively simple, intuitive approach that can be accepted by managers and other decision-makers; (3) ANP allows for more complex relationship among the decision levels and attributes as it does not require a strict hierarchical structure; and (4) ANP is more adapted with real world problems. In spite that fact that the ANP technique is capable of solving a sophisticated decision making problem, this method is less effective in conveying the imprecision and fuzziness characteristics (Bashiri et al. 2011).

The main aim of the study is to evaluate the critical factors of application of nanotechnology in construction and provide a decision support framework to carefully calculate the relative weight of the evaluation criteria. For achieving the aim, the intuitionistic fuzzy ANP method is employed to obtain the relative weights.

The remainder of this paper is organized as follows. The intuitionistic fuzzy set is illustrated in Section 1. In Section 2, the ANP technique is briefly described. The proposed model is clearly described in Section 3. In Section 4, the implementation of the proposed model is accomplished to evaluate the critical factors of the appli- cation of nanotechnology in the construction industry. Finally, conclusions are presented.

\section{Intuitionistic fuzzy set}

Over the last three decades, fuzzy logic theory has been extensively obtained great success in the field of science, engineering, and management. The fuzzy theory, first introduced by Zadeh in 1965 for dealing with vagueness appearing in real-world problems, is a powerful mathematical tool (Zadeh 1965). This technique employs the membership functions, the cornerstone of fuzzy concepts, to handle the uncertainty involved in the process of formulation.

However, in order to describe a fuzzy set, Zadeh applied a single membership function. In other words, the single membership function simultaneously represents two opposite characteristics of a fuzzy concept. Namely, the degree of belongingness to a fuzzy set is determined by a membership function, in which each element $x$ of the universe of discourse has a real number $\mu(x)$ belonging to the closed interval $[0,1]$. As a result, the degree of non-belongingness is inevitably equal to $1-\mu(x)$. Therefore, the fuzzy set is only able to describe fuzziness "this and also that" and is not capable of representing the neutral state, i.e., neither supporting nor opposing (Li 2014).

However, this limitation of the fuzzy set leads to new challenges in some sophisticated problems. Hence, the intuitionistic fuzzy set, represented by three membership functions including membership (the degree of belongingness) and nonmembership (the degree of nonbelongingness), and non-determinacy (the degree of hesitation) functions, was firstly introduced by Atanassov (1999). Based on the principal concepts of the intuitionistic fuzzy set, a typical set contains of three components: support, opposition, and neutrality. In other words, the intuitionistic fuzzy set is able to describe fuzziness of "neither this nor that" (Li 2014).

Hence, the intuitionistic fuzzy set is a general form of the fuzzy set. The fuzzy set has obtained a great success in practical applications and theoretical researches such as equipment selection (Yazdani-Chamzini 2014a), corporate social responsibility (Skarmeas et al. 2014), operations research (Broumi, Smarandache 2014; Alcantud 2016; Gonçalves et al. 2016; Sun et al. 2014, 2017; Pask et al. 2017; Fan et al. 2017), performance evaluation (Rabbani et al. 2014; Onat et al. 2016), risk assessment (Yazdani-Chamzini 2014b; Abdullah, Najib 2014); site selection (Shariati et al. 2014), and supplier selection (Kar 2015). It can be anticipated that the intuitionistic fuzzy set has a success prospect for modelling a decision making problem, in which expert's knowledge and experience is required for formulation of the problem under consideration.

According to the potential applications of the intuitionistic fuzzy set, this technique has been applied by different researches. Liu and Wang (2007) presented 
new methods for solving multi-criteria decision-making problem in an intuitionistic fuzzy environment. They developed an evaluation function for the decision-making problem to measure the degrees to which alternatives satisfy and do not satisfy the decision-maker's requirement.

Szmidt and Kacprzyk (2001) introduced a measure of entropy for an intuitionistic fuzzy set. Atanassov and Gargov (1998) constructed two versions of intuitionistic fuzzy propositional calculus (IFPC) and a version of intuitionistic fuzzy predicate logic. A new method for handling multicriteria fuzzy decision-making problems based on intuitionistic fuzzy sets is proposed by Lin et al. (2007).

A new concept of the optimization problem under uncertainty based on intuitionistic fuzzy sets is proposed by Angelov (1997). The proposed model is an extension of fuzzy optimization in which the degrees of rejection of objective(s) and of constraints are considered together with the degrees of satisfaction. A new definition of the degree of similarity between IFSs is introduced by Dengfeng and Chuntian (2002). They applied the similarity measures of IFSs to pattern recognitions.

Boran et al. (2009) proposed a combination model based on intuitionistic fuzzy set and TOPSIS method to select appropriate supplier in group decision making environment. Li (2005) developed the multiattribute decision making methods using intuitionistic fuzzy sets and linear programming models to generate optimal weights for attributes. Xu and Zhao (2016) presented an overview on the existing intuitionistic fuzzy decision making theories and methods from the perspective of information fusion, involving the determination of attribute weights, the aggregation of intuitionistic fuzzy information and the ranking of alternatives.

$\mathrm{Li}$ (2010) introduced the concept of a triangular intuitionistic fuzzy number (TIFN) as a special case of the
IFN and develop a new methodology for ranking TIFNs. An algorithm of the intuitionistic fuzzy fault-tree analysis is proposed by Shu et al. (2006) to calculate fault interval of system components and to find the most critical system component for the managerial decision-making based on some basic definitions.

An intuitionistic fuzzy set $A$ in $E$ is mathematically defined as:

$$
A=\left\{\left\langle x, \mu_{A}(x), v_{A}(x)\right\rangle \mid x \in E\right\},
$$

where the functions:

$$
\mu_{A}: E \rightarrow[0,1]
$$

and

$$
v_{A}: E \rightarrow[0,1] .
$$

The degree of membership and the degree of nonmembership of the element $x \in E$, respectively, can be described for every $x \in E$ as:

$$
0 \leq \mu_{A}(x)+v_{A}(x) \leq 1 .
$$

Now, a typical fuzzy set can be defined as:

$$
A=\left\{\left\langle x, \mu_{A}(x), 1-\mu_{A}(x)\right\rangle \mid x \in E\right\} .
$$

The degree of non-determinacy (or uncertainty) of the element $x \in E$ to the intuitionistic fuzzy set $A$ is defined by Atanassov (1999) as the following form:

$$
\pi_{A}(x)=1-\mu_{A}(x)-v_{A}(x) .
$$

For two intuitionistic fuzzy sets $A$ and $B$, the following relations and operations can be defined:

$$
\begin{gathered}
A \subset B \text { if and only if }(\forall x \in E)\left(\mu_{A}(x) \leq \mu_{B}(x) \& v_{A}(x) \geq v_{B}(x)\right) ; \\
A \supset B \text { if and only if } B \subset A ; \\
A=B \text { if and only if }(\forall x \in E)\left(\mu_{A}(x)=\mu_{B}(x) \& v_{A}(x)=v_{B}(x)\right) ; \\
\bar{A}=\left\{\left\langle x, v_{A}(x), \mu_{A}(x)\right\rangle \mid x \in E\right\} ; \\
A \cap B=\left\{\left\langle x, \min \left(\mu_{A}(x), \mu_{B}(x)\right), \max \left(v_{A}(x), v_{B}(x)\right)\right\rangle \mid x \in E\right\} ; \\
A \cup B=\left\{\left\langle x, \max \left(\mu_{A}(x), \mu_{B}(x)\right), \min \left(v_{A}(x), v_{B}(x)\right)\right\rangle \mid x \in E\right\} ; \\
A+B=\left\{\left\langle x, \mu_{A}(x)+\mu_{B}(x)-\mu_{A}(x) \cdot \mu_{B}(x), v_{A}(x) \cdot v_{B}(x)\right\rangle \mid x \in E\right\} ; \\
A . B=\left\{\left\langle x, \mu_{A}(x) \cdot \mu_{B}(x), v_{A}(x)+v_{B}(x)-v_{A}(x) \cdot v_{B}(x)\right\rangle \mid x \in E\right\} .
\end{gathered}
$$


The most popular distances between intuitionistic fuzzy sets $\mathrm{A}$ and $\mathrm{B}$ in $X=\left\{x_{1}, x_{2}, \ldots, x_{n}\right\}$ can be defined as:

The Hamming distance:

$$
d(A, B)=\sum_{i=1}^{n}\left(\left|\mu_{A}\left(x_{i}\right)-\mu_{B}\left(x_{i}\right)\right|+\left|v_{A}\left(x_{i}\right)-v_{B}\left(x_{i}\right)\right|+\left|\pi_{A}\left(x_{i}\right)-\pi_{B}\left(x_{i}\right)\right|\right) .
$$

The Euclidean distance:

$$
e(A, B)=\sqrt{\sum_{i=1}^{n}\left(\mu_{A}\left(x_{i}\right)-\mu_{B}\left(x_{i}\right)\right)^{2}+\left(v_{A}\left(x_{i}\right)-v_{B}\left(x_{i}\right)\right)^{2}+\left(\pi_{A}\left(x_{i}\right)-\pi_{B}\left(x_{i}\right)\right)^{2}},
$$

where:

$$
0 \leq d(A, B) \leq 2 n
$$

and

$$
0 \leq e(A, B) \leq \sqrt{2 n} .
$$

\section{The ANP technique}

The Analytic network process (ANP), developed by Saaty (1996), is a generalization form of the analytical hierarchy process (AHP) technique. This technique solves a decision making (DM) problem by decomposing a sophisticated problem into a limited number of simple issues. This technique can take into account all relationships, including linear and non-linear interactions, between the elements; whereas, the AHP method neglects to consider the interrelationships among the elements. Figure 1 depicts the structures of hierarchy and network.

From the figure, it can be seen that a hierarchy shows a top down structure; whereas, a network structure denotes a non-linear pattern comprising arcs in all directions. These arcs show the relationships among elements. The ANP technique extends the AHP to facilitate the process of formulating the problems with feed-back and dependence (Fouladgar et al. 2012). The ANP technique includes the following steps (Azimi et al. 2011):

Step 1. Construct the hierarchy and network model.

Step 2. Assuming that there is no dependence among criteria, the pairwise comparison matrices are made.

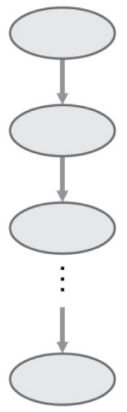

B

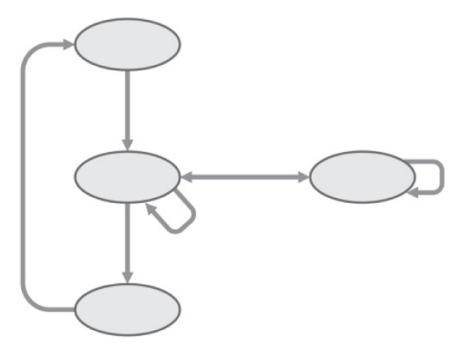

Fig. 1. Structure of hierarchy (A) and network (B) (Azimi et al. 2011)
Step 3. Inner dependence among criteria is extracted by analyzing the impact of each factor on every other factor by using pairwise comparisons.

Step 4. The interdependent weights of criteria are calculated by multiplying the weights obtained in Step 2 with the previous step.

Step 5. Rank the criteria based on their corresponding values.

\section{The proposed model}

The model proposed for ranking a decision making issue is illustrated in the following part. The proposed model comprises an eight-step procedure described as follows.

Step 1. Definition of the MCDM problem.

Step 2. Formulation of the MCDM problem and identification of the evaluation criteria.

Step 3. Definition of the linguistic variables and the corresponding intuitionistic fuzzy functions.

Step 4. Design of an AHP-based questionnaire based on the two-by-two comparisons in the form of the linguistic variables. Then the linguistic variables are transferred into corresponding intuitionistic fuzzy values.

Step 5. Computation of the consistency ratio (CR) of the intuitionistic fuzzy judgement matrix. Since the intuitionistic fuzzy matrix comprises the hesitation value $(\pi(x))$, the degree of consistency is calculated by using the following equation retrieved from Saaty (1980):

$$
\mathrm{CR}=\frac{\left(\left(\lambda_{\max }-n\right) /(n-1)\right)}{R I},
$$

where $n$ represents the size of the matrix; $R I$ addresses the value of random indices (as shown in Table 1); and $\left(\lambda_{\max }-n\right)$ denotes the average value of the hesitation value (Abdullah, Najib 2016). Three acceptable levels are set for CR values: 1) 0.05 for 3-by-3 matrix, 2) 0.08 for 4-by-4 matrix, and 3) 0.1 for all other matrices (Saaty 1996).

Step 5. Calculation of the importance weights of the main and sub-criteria.

Step 6. Determination of the inner dependence matrix. 
Table 1. Random indices of sizes of matrices

\begin{tabular}{cccccccccc}
\hline$n$ & $1-2$ & 3 & 4 & 5 & 6 & 7 & 8 & 9 \\
\hline$R I$ & 0 & 0.58 & 0.9 & 1.12 & 1.24 & 1.32 & 1.41 & 1.45 \\
\hline
\end{tabular}

Step 7. Computation of the overall weight of the subcriteria.

Step 8. Priority of the criteria based on the final rank.

For better understanding, the proposed model is schematically depicted in Figure 2. From the figure, it can be seen that there is a systematic and analytical approach combining quantitative and qualitative components with the intuitionistic fuzzy set, in which all aspects of a uncertainty is taken into account and the results are more adapted with real world problems, to make a comparison among a limited number of criteria for obtaining the most critical factor in building construction. The merit of using the intuitionistic fuzzy set is to precisely formulate the problem under consideration for achieving a completely reliable and sure result.

\section{The implementation of proposed model}

Market consumption of nanomaterials is steadily increasing; so that, world demand for nanomaterials will rise more than two-and-a-half times to $\$ 5.5$ billion in 2016 (Freedonia 2012). According to the Freedonia Group, worldwide demand for nanomaterials in construction sector is approximately $3 \%$. It is expected that the demand for nanomaterials will grow to $\$ 100$ billion by 2025 and the contribution of construction sector is around $7 \%$. Therefore, nanomaterials and nanotechnology propose fascinating new opportunities in the construction sector. The nanotechnology in the construction industry is concentrated in four parts: (1) cement-bound construction materials; (2) noise reduction and thermal insulation or temperature regulation; (3) surface coatings to improve the functionality of various materials, and (4) fire protection.

According to the key role of nanotechnology in the construction industry, this paper uses an IFS-ANP based model to provide a framework for evaluation of the critical factors of the application of nanotechnology in the construction industry.

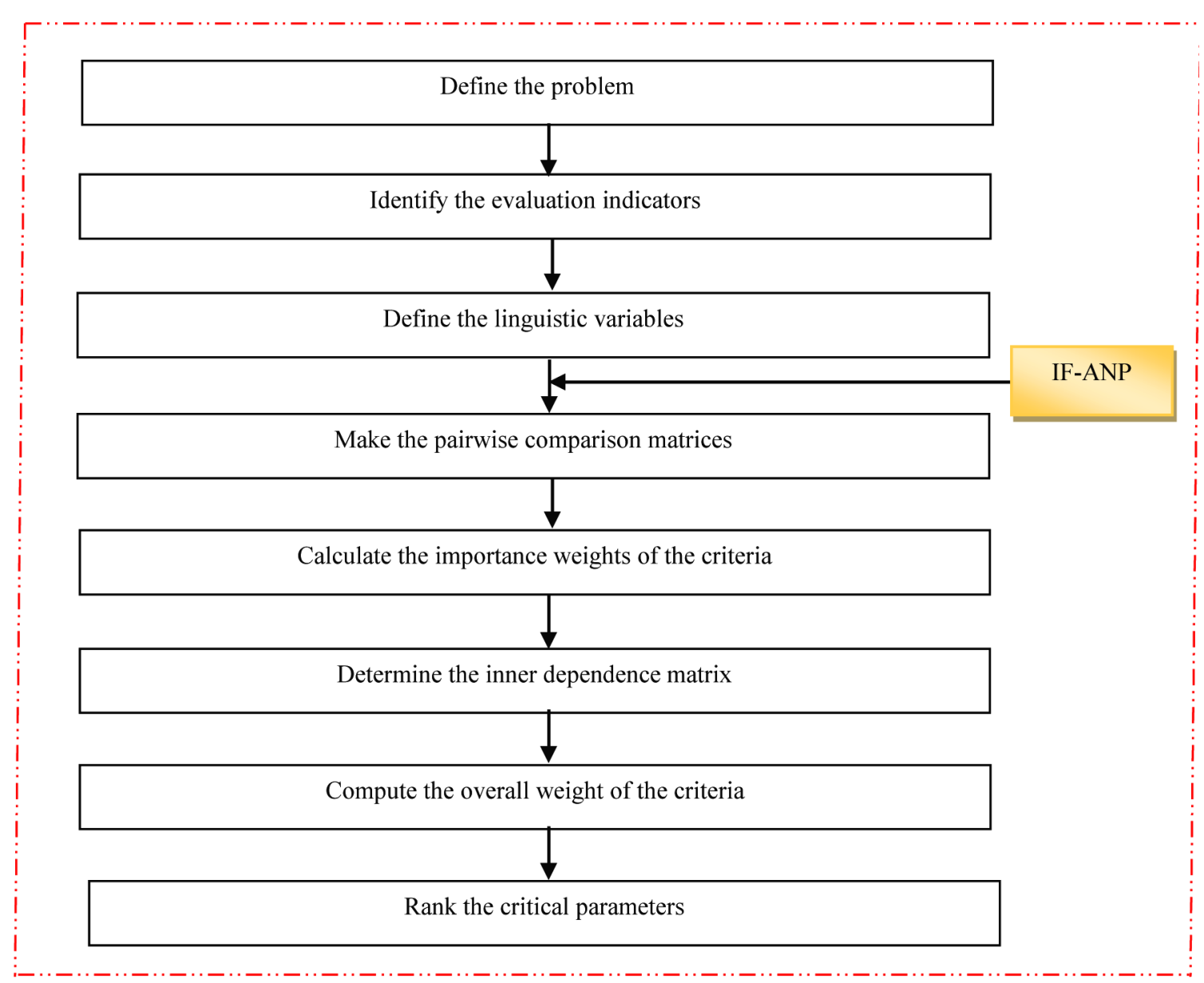

Fig. 2. The proposed model 
Table 2. Criteria and sub-criteria

\begin{tabular}{|c|c|c|}
\hline The overall goal & Main-criteria & Sub-criteria \\
\hline \multirow{10}{*}{ 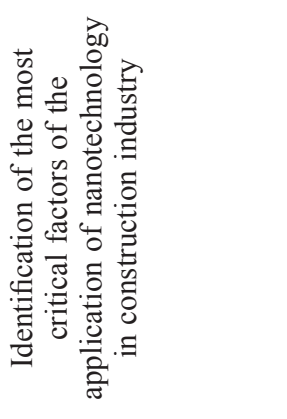 } & \multirow[t]{2}{*}{ Cost (C1) } & Capital cost $(\mathrm{C} 11)$ \\
\hline & & Maintenance $(\mathrm{C} 12)$ \\
\hline & Health (C2) & Health (C2) \\
\hline & Safety (C3) & Safety (C3) \\
\hline & Environment $(\mathrm{C} 4)$ & Environment (C4) \\
\hline & \multirow[t]{5}{*}{ Performance (C5) } & Durability (C51) \\
\hline & & Ductility (C52) \\
\hline & & Corrosion protection coatings (C53) \\
\hline & & Weight (C54) \\
\hline & & Strength (C55) \\
\hline
\end{tabular}

By using an organized approach, comprising literature survey and face to face interview, a total number of 14 key factors are identified. Then, a screening process is conducted to find the most important criteria. Finally, ten criteria, including capital cost (C11), maintenance (C12), health (C2), safety (C3), environment (C4), durability (C51), ductility (C52), corrosion protection coatings (C53), weight (C54), and strength (C55), are identified as the most critical factors (shown in Table 2 and Fig. 3). The identified criteria are grouped into five main-criteria as presented in Table 2. For gathering the information, eight questionnaires employing the two-by-two compari- son framework based on the scale given in Table 3 are designed to obtain the relative weights of the evaluation criteria. A sample of the questionnaires filled by the expert team is presented in Table 4. Then, the linguistic variables are converted into their corresponding intuitionistic fuzzy values presented in Table 3 . The results of the quantification process are shown in Table 5 . The calculation of the CR value is accomplished based on Eqn (19) to measure the degree of the consistency of the pair-wise comparison matrix as shown in the last row of Table 5. Since the CR value is less than 0.1 , the decision matrix is consistent. Then, an arithmetic average process (AVP), as

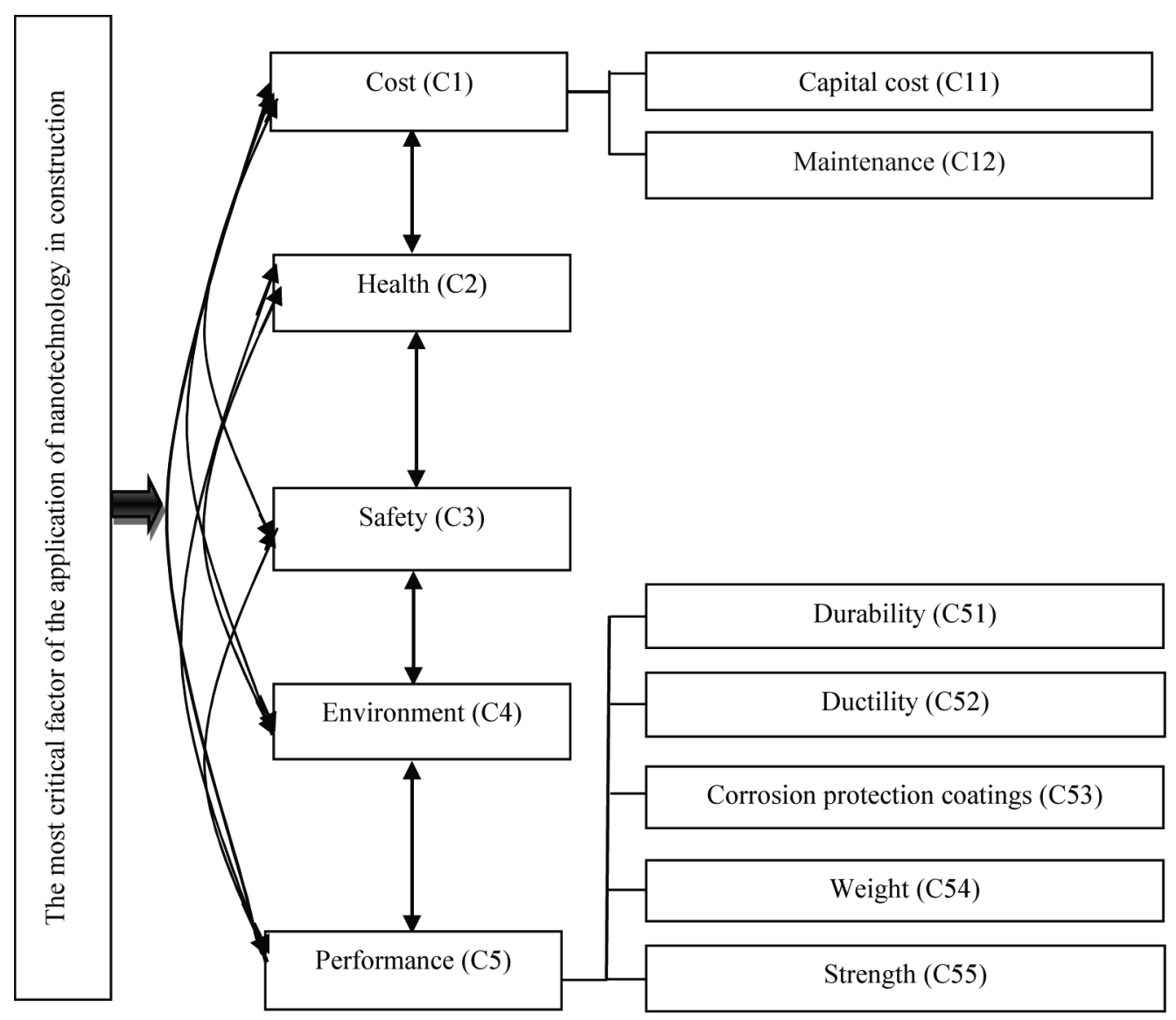

Fig. 3. Decision hierarchy structure 
Table 3. Linguistic variables and intuitionistic fuzzy numbers

\begin{tabular}{|c|c|c|}
\hline Intuitionistic fuzzy number & Linguistic variable & Definition $\left(a_{i j}\right)$ \\
\hline$(1,0.0,0.0)$ & Extremely Important (EI) & Objective $i$ is extremely important than $j$ objective \\
\hline$(0.9,0.0,0.1)$ & Strong Important (SI) & Objective $i$ is strong important than $j$ objective \\
\hline$(0.8,0.1,0.1)$ & Very Important (VI) & Objective $i$ is very important than $j$ objective \\
\hline$(0.7,0.2,0.1)$ & Moderately Important (MI) & Objective $i$ is medium important than $j$ objective \\
\hline$(0.6,0.3,0.1)$ & Important (I) & Objective $i$ is important than $j$ objective \\
\hline$(0.5,0.4,0.1)$ & Less Important (LI) & Objective $i$ is less important than $j$ objective \\
\hline$(0.5,0.5,0.0)$ & Exactly Equal (E) & Objective $i$ is exactly equal to $j$ objective \\
\hline$(0.45,0.45,0.1)$ & Approximately Equal (AE) & Objective $i$ is approximately equal to $j$ objective \\
\hline$(0.4,0.5,0.1)$ & Less Unimportant (LU) & Objective $i$ is less unimportant than $j$ objective \\
\hline$(0.3,0.6,0.1)$ & Unimportant (U) & Objective $i$ is unimportant than $j$ objective \\
\hline$(0.2,0.7,0.1)$ & Moderately Unimportant (MU) & Objective $i$ is medium unimportant than $j$ objective \\
\hline$(0.1,0.8,0.1)$ & Very Unimportant (VU) & Objective $i$ is very unimportant than $j$ objective \\
\hline$(0.0,0.9,0.1)$ & Strong Unimportant (SU) & Objective $i$ is strong unimportant than $j$ objective \\
\hline$(0.0,0.0,1)$ & Extremely Unimportant (EU) & Objective $i$ is extremely unimportant than $j$ objective \\
\hline
\end{tabular}

Table 4. A questionnaire filled by expert team

\begin{tabular}{cccccc}
\hline & C1 & C2 & C3 & C4 & C5 \\
\hline C1 & E & I & LI & MI & I \\
C2 & U & E & LU & LI & LU \\
C3 & LU & LI & E & I & AE \\
C4 & MU & LU & U & E & LU \\
C5 & U & LI & AE & LI & E \\
\hline
\end{tabular}

presented in Eqn (20), is conducted to obtain the aggregated value of each row of the intuitionistic fuzzy judgment matrix:

$$
A V P=\frac{1}{n} \sum_{k=1}^{n} w_{i}^{k}
$$

where $\mathrm{n}$ indicates the number of decision makers; $w_{i}^{k}$ addresses the weight allocated by the k-th decision maker.

The results of the AVP are shown in Table 5. Next, the calculation of the importance weights of the criteria is conducted by using the following equations to transfer the intuitionistic fuzzy values into crisp ones for further analysis such as evaluation and classification:

$$
\begin{aligned}
& \overline{\bar{w}}_{i}=-\frac{1}{n \ln 2} \\
& {\left[\mu_{i} \ln \mu_{i}+v_{i} \ln v_{i}-\left(1-\pi_{i}\right) \ln \left(1-\pi_{i}\right)-\pi_{i} \ln 2\right],}
\end{aligned}
$$

here:

if $\mu_{i}=0, \quad v_{i}=0, \quad \pi_{i}=0$, then $\mu_{i} \ln \mu_{i}=0$, $v_{i} \ln v_{i}=0,\left(1-\pi_{i}\right) \ln \left(1-\pi_{i}\right)=0$,

and if $\mu_{i}=1, v_{i}=0, \pi_{i}=0$, then $\mu_{i} \ln \mu_{i}=0$, $v_{i} \ln v_{i}=0,\left(1-\pi_{i}\right) \ln \left(1-\pi_{i}\right)=0$, respectively.

Therefore, the final entropy weight $\left(w_{i}\right)$ of each intuitionistic fuzzy matrix is obtained by using the following equation:

$$
w_{i}=\frac{1-\overline{\bar{w}}_{i}}{n-\sum_{j=1}^{n} \overline{\bar{w}}_{i}},
$$

Table 5. The relative weights of the main criteria without the assumption of interdependency

\begin{tabular}{cccccccc}
\hline & $\mathrm{C} 1$ & $\mathrm{C} 2$ & $\mathrm{C} 3$ & $\mathrm{C} 4$ & $\mathrm{C} 5$ & $\mathrm{AVP}$ & $w_{i}$ \\
\hline $\mathrm{C} 1$ & $(0.5,0.5,0.0)$ & $(0.6,0.3,0.1)$ & $(0.5,0.4,0.1)$ & $(0.7,0.2,0.1)$ & $(0.6,0.3,0.1)$ & $(0.58,0.34,0.08)$ & 0.201 \\
$\mathrm{C} 2$ & $(0.3,0.6,0.1)$ & $(0.5,0.5,0.0)$ & $(0.4,0.5,0.1)$ & $(0.5,0.4,0.1)$ & $(0.4,0.5,0.1)$ & $(0.42,0.5,0.08)$ & 0.199 \\
$\mathrm{C} 3$ & $(0.4,0.5,0.1)$ & $(0.5,0.4,0.1)$ & $(0.5,0.5,0.0)$ & $(0.6,0.3,0.1)$ & $(0.45,0.45,0.1)$ & $(0.49,0.43,0.08)$ & 0.199 \\
$\mathrm{C} 4$ & $(0.2,0.7,0.1)$ & $(0.4,0.5,0.1)$ & $(0.3,0.6,0.1)$ & $(0.5,0.5,0.0)$ & $(0.4,0.5,0.1)$ & $(0.36,0.56,0.08)$ & 0.201 \\
$\mathrm{C} 5$ & $(0.3,0.6,0.1)$ & $(0.5,0.4,0.1)$ & $(0.45,0.45,0.1)$ & $(0.5,0.4,0.1)$ & $(0.5,0.5,0.0)$ & $(0.45,0.47,0.08)$ & 0.199 \\
\hline \multicolumn{7}{c}{$\mathrm{CR}=0.089$} \\
\hline
\end{tabular}


where:

$$
\sum_{j=1}^{n} w_{i}=1
$$

The last column of Table 5 reflects the final entropy weight $\left(w_{i}\right)$ obtained for the evaluation criteria without the assumption of interdependency. The importance weights of sub-criteria and the values of the CR index are obtained in the same ways as presented in Tables 6 and 7 .

In the next step, the inner-dependence matrix of each main criterion with respect to the other main-criteria is obtained to compute the interdependent weights of the main-criteria. The interdependency among the main-criteria is calculated by evaluating the impact of each criterion on every other criterion in the form of the intuitionistic fuzzy pairwise comparisons. Tables $8-12$ use the

Table 6. The importance weights of the cost sub-criteria

\begin{tabular}{ccccc}
\hline & C11 & C12 & AVP & $w_{i}$ \\
\hline C11 & $(0.5,0.5,0.0)$ & $(0.6,0.3,0.1)$ & $(0.82,0.16,0.02)$ & 0.524 \\
C12 & $(0.3,0.6,0.1)$ & $(0.5,0.5,0.0)$ & $(0.76,0.22,0.02)$ & 0.476 \\
\hline \multicolumn{5}{c}{ CR $=0.00$} \\
\hline
\end{tabular}

Table 7. The importance weights of the performance sub-criteria

\begin{tabular}{|c|c|c|c|c|c|c|c|}
\hline & C51 & C52 & C53 & C54 & C55 & AVP & $w_{i}$ \\
\hline C51 & $(0.5,0.5,0.0)$ & $(0.7,0.2,0.1)$ & $(0.45,0.45,0.1)$ & $(0.7,0.2,0.1)$ & $(0.4,0.5,0.1)$ & $(0.55,0.37,0.08)$ & 0.2003 \\
\hline $\mathrm{C} 52$ & $(0.2,0.7,0.1)$ & $(0.5,0.5,0.0)$ & $(0.4,0.5,0.1)$ & $(0.4,0.5,0.1)$ & $(0.3,0.6,0.1)$ & $(0.36,0.56,0.08)$ & 0.2006 \\
\hline \multicolumn{5}{|c|}{$\begin{array}{l}\text { C53 } \\
(0.45,0.45,0.1) \\
(0.5,0.4,0.1) \\
(0.5,0.5,0.0) \\
(0.5,0.4,0.1)\end{array}$} & $(0.4,0.5,0.1)$ & $(0.47,0.45,0.08)$ & 0.199 \\
\hline $\mathrm{C} 54$ & $(0.2,0.7,0.1)$ & $(0.5,0.4,0.1)$ & $(0.4,0.5,0.1)$ & $(0.5,0.5,0.0)$ & $(0.3,0.6,0.1)$ & $(0.38,0.54,0.08)$ & 0.200 \\
\hline C55 & $(0.5,0.4,0.1)$ & $(0.6,0.3,0.1)$ & $(0.5,0.4,0.1)$ & $(0.6,0.3,0.1)$ & $(0.5,0.5,0.0)$ & $0.54,0.38,0.08)$ & 0.200 \\
\hline
\end{tabular}

Table 8. The interdependence matrix of the main criteria with respect to "cost criterion"

\begin{tabular}{ccccccc}
\hline $\mathrm{C} 1$ & $\mathrm{C} 2$ & $\mathrm{C} 3$ & $\mathrm{C} 4$ & $\mathrm{C} 5$ & AVP & $w_{i}$ \\
\hline $\mathrm{C} 2$ & $(0.5,0.5,0.0)$ & $(0.3,0.6,0.1)$ & $(0.4,0.5,0.1)$ & $(0.45,0.45,0.1)$ & $(0.53,0.41,0.06)$ & 0.2472 \\
$\mathrm{C} 3$ & $(0.6,0.3,0.1)$ & $(0.5,0.5,0.0)$ & $(0.7,0.2,0.1)$ & $(0.6,0.3,0.1)$ & $(0.68,0.26,0.06)$ & 0.2578 \\
$\mathrm{C} 4$ & $(0.5,0.4,0.1)$ & $(0.2,0.7,0.1)$ & $(0.5,0.5,0.0)$ & $(0.4,0.5,0.1)$ & $(0.52,0.42,0.06)$ & 0.2470 \\
$\mathrm{C} 5$ & $(0.45,0.45,0.1)$ & $(0.3,0.6,0.1)$ & $(0.5,0.4,0.1)$ & $(0.5,0.5,0.0)$ & $(0.55,0.39,0.06)$ & 0.2480 \\
\hline
\end{tabular}

Table 9. The interdependence matrix of the main criteria with respect to "health criterion"

\begin{tabular}{cccccccc}
\hline $\mathrm{C} 2$ & $\mathrm{C} 1$ & $\mathrm{C} 3$ & $\mathrm{C} 4$ & $\mathrm{C} 5$ & $\mathrm{AVP}$ & $w_{i}$ \\
\hline $\mathrm{C} 1$ & $(0.5,0.5,0.0)$ & $(0.7,0.2,0.1)$ & $(0.8,0.1,0.1)$ & $(0.5,0.4,0.1)$ & $(0.7,0.24,0.06)$ & 0.2592 \\
$\mathrm{C} 3$ & $(0.2,0.7,0.1)$ & $(0.5,0.5,0.0)$ & $(0.45,0.45,0.1)$ & $(0.4,0.5,0.1)$ & $(0.51,0.43,0.06)$ & 0.2458 \\
$\mathrm{C} 4$ & $(0.1,0.8,0.1)$ & $(0.45,0.45,0.1)$ & $(0.5,0.5,0.0)$ & $(0.3,0.6,0.1)$ & $(0.47,0.47,0.06)$ & 0.2454 \\
$\mathrm{C} 5$ & $(0.4,0.5,0.1)$ & $(0.5,0.4,0.1)$ & $(0.6,0.3,0.1)$ & $(0.5,0.5,0.0)$ & $(0.6,0.34,0.06)$ & 0.2497 \\
\hline
\end{tabular}

Table 10. The interdependence matrix of the main criteria with respect to "safety criterion"

\begin{tabular}{ccccccc}
\hline C3 & C1 & C2 & C4 & C5 & AVP & $w_{i}$ \\
\hline C1 & $(0.5,0.5,0.0)$ & $(0.8,0.1,0.1)$ & $(0.9,0.0,0.1)$ & $(0.5,0.4,0.1)$ & $(0.74,0.2,0.06)$ & 0.2625 \\
C2 & $(0.1,0.8,0.1)$ & $(0.5,0.5,0.0)$ & $(0.5,0.4,0.1)$ & $(0.3,0.6,0.1)$ & $(0.48,0.46,0.06)$ & 0.2432 \\
C4 & $(0.0,0.9,0.1)$ & $(0.4,0.5,0.1)$ & $(0.5,0.5,0.0)$ & $(0.2,0.7,0.1)$ & $(0.42,0.52,0.06)$ & 0.2438 \\
C5 & $(0.4,0.5,0.1)$ & $(0.6,0.3,0.1)$ & $(0.7,0.2,0.1)$ & $(0.5,0.5,0.0)$ & $(0.64,0.3,0.06)$ & 0.2505 \\
\hline
\end{tabular}


Table 11. The interdependence matrix of the main criteria with respect to "environmental criterion"

\begin{tabular}{ccccccc}
\hline C4 & C1 & C2 & C3 & C5 & AVP & $w_{i}$ \\
\hline C1 & $(0.5,0.5,0.0)$ & $(0.7,0.2,0.1)$ & $(0.8,0.1,0.1)$ & $(0.6,0.3,0.1)$ & $(0.72,0.22,0.06)$ & 0.2619 \\
C2 & $(0.2,0.7,0.1)$ & $(0.5,0.5,0.0)$ & $(0.45,0.45,0.1)$ & $(0.4,0.5,0.1)$ & $(0.51,0.43,0.06)$ & 0.2458 \\
C3 & $(0.1,0.8,0.1)$ & $(0.45,0.45,0.1)$ & $(0.5,0.5,0.0)$ & $(0.5,0.4,0.1)$ & $(0.51,0.43,0.06)$ & 0.2458 \\
C5 & $(0.3,0.6,0.1)$ & $(0.5,0.4,0.1)$ & $(0.4,0.5,0.1)$ & $(0.5,0.5,0.0)$ & $(0.54,0.4,0.06)$ & 0.2466 \\
\hline
\end{tabular}

Table 12. The interdependence matrix of the main criteria with respect to "performance criterion"

\begin{tabular}{ccccccc}
\hline $\mathrm{C} 5$ & $\mathrm{C} 1$ & $\mathrm{C} 2$ & $\mathrm{C} 3$ & $\mathrm{C} 4$ & AVP & $w_{i}$ \\
\hline $\mathrm{C} 1$ & $(0.5,0.5,0.0)$ & $(0.7,0.2,0.1)$ & $(0.6,0.3,0.1)$ & $(0.6,0.3,0.1)$ & $(0.68,0.26,0.06)$ & 0.2576 \\
$\mathrm{C} 2$ & $(0.2,0.7,0.1)$ & $(0.5,0.5,0.0)$ & $(0.3,0.6,0.1)$ & $(0.45,0.45,0.1)$ & $(0.49,0.45,0.06)$ & 0.2462 \\
$\mathrm{C} 3$ & $(0.3,0.6,0.1)$ & $(0.6,0.3,0.1)$ & $(0.5,0.5,0.0)$ & $(0.5,0.4,0.1)$ & $(0.58,0.36,0.06)$ & 0.2492 \\
$\mathrm{C} 4$ & $(0.3,0.6,0.1)$ & $(0.45,0.45,0.1)$ & $(0.4,0.5,0.1)$ & $(0.5,0.5,0.0)$ & $(0.53,0.41,0.06)$ & 0.2470 \\
\hline
\end{tabular}

intuitionistic fuzzy judgment matrices to show the interdependency among the main-criteria. The matrices are constructed by asking "What is the relative importance of 'one criterion' when compared with 'one another criterion' on controlling 'another criterion'?". The same approach aforementioned in above is applied for calculating the relative weights of the main criteria as presented in the last column of Tables 8-12.

Then, the overall weights of the main-criteria are computed by using the relative weights obtained in the previous stages. For achieving the aim, the interdependent weights of the main criteria are multiplied with the local weights of the main criteria as follows:

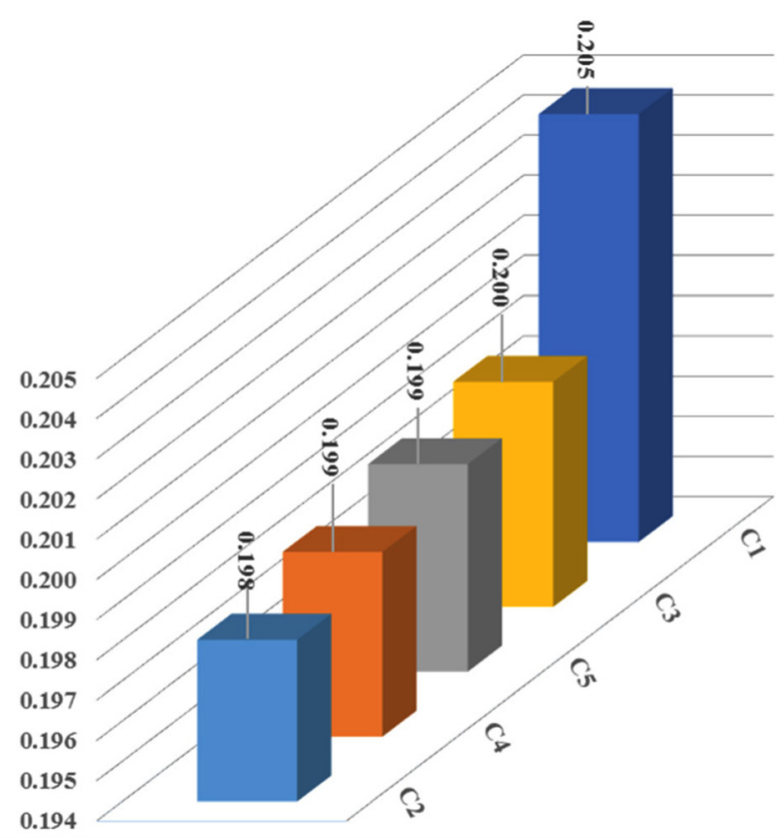

Fig. 4. The overall weight of the main-criteria

$\begin{aligned} {\left[\begin{array}{l}C 1 \\ C 2 \\ C 3 \\ C 4 \\ C 5\end{array}\right]=} & {\left[\begin{array}{lllll}1.0000 & 0.2592 & 0.2625 & 0.2619 & 0.2576 \\ 0.2472 & 1.0000 & 0.2432 & 0.2458 & 0.2462 \\ 0.2578 & 0.2458 & 1.0000 & 0.2458 & 0.2492 \\ 0.2470 & 0.2454 & 0.2438 & 1.0000 & 0.2470 \\ 0.2480 & 0.2497 & 0.2505 & 0.2466 & 1.0000\end{array}\right] \times } \\ & {\left[\begin{array}{l}0.2014 \\ 0.1994 \\ 0.1993 \\ 0.2007 \\ 0.1992\end{array}\right]=\left[\begin{array}{l}0.2046 \\ 0.1980 \\ 0.1996 \\ 0.1986 \\ 0.1992\end{array}\right] . }\end{aligned}$

From the above matrix, the values are different from when the interdependent weights and dependencies are neglected. The overall results change from 0.2014 to $0.2046,0.1994$ to $0.1980,0.1993$ to $0.1996,0.2007$ to 0.1986 , and 0.1992 to 0.1992 for the priority values of criteria $\mathrm{C} 1, \mathrm{C} 2, \mathrm{C} 3, \mathrm{C} 4$, and $\mathrm{C} 5$, respectively. As well as, the ranking order varies from $\mathrm{C} 1>\mathrm{C} 3>\mathrm{C} 2>\mathrm{C} 3>\mathrm{C} 5$ to $\mathrm{C} 1>\mathrm{C} 3>\mathrm{C} 5>\mathrm{C} 4>\mathrm{C} 2$. Figure 4 schematically depicts the overall weight of the main-criteria.

In the next step, the overall weights of the sub-criteria are calculated by multiplying the overall weights of the main criteria obtained in the previous step with those of the sub-criteria calculated in Step 5. The overall weights of sub-criteria are presented in Table 13. Figure 5 graphically shows the final weights of the sub-criteria. From the figure, it can be shown that the criterion "safety" is determined as the most critical parameter influencing the application of nanotechnology in the construction industry. As seen in Table 13, the criterion "corrosion protection coatings" is located in the end of list of priorities. As a consequence, the merit of using the intuitionistic fuzzy set is to accurately handle the uncertainty arisen 
Table 13. The overall weights of the sub-criteria

\begin{tabular}{ccccccccccc}
\hline C11 & C12 & C2 & C3 & C4 & C51 & C52 & C53 & C54 & C55 \\
\hline 0.1072 & 0.0974 & 0.1980 & 0.1996 & 0.1986 & 0.0399 & 0.0400 & 0.0396 & 0.0398 & 0.0398 \\
\hline
\end{tabular}

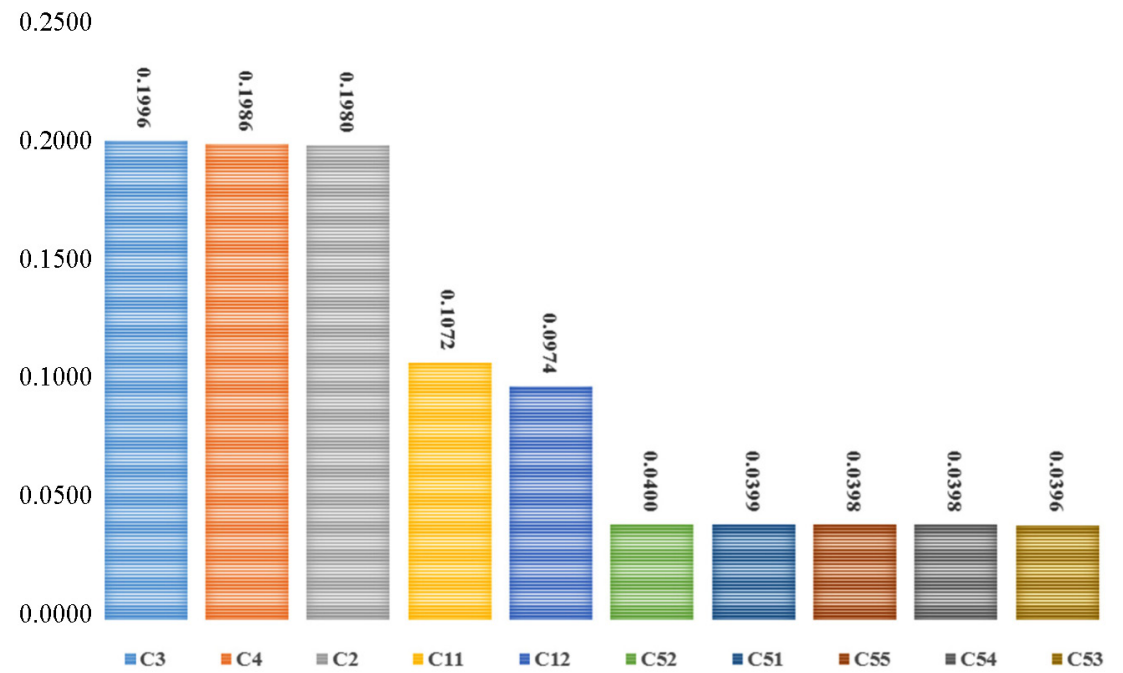

Fig. 5. The overall weights of the sub-criteria

from the complexity in the process of formulation in the form of a three dimension function, including the degree of belongingness, the degree of nonbelongingness, and the degree of hesitation, for a more reliable result.

\section{Conclusions}

Construction sector is faced with an enormous number of challenges pertaining to materials and their properties ranging from capital and maintenance cost to health, safety, environmental, and performance issues. Many recent developments are in response to such challenges. Nanotechnology offers a large number of advantages for a diversity of applications in construction industry. The application of nanotechnology in the construction industry varies from making more durable construction components to fire protection materials. However, the identification of the critical factors of the application of nanotechnology in the construction sector help authorities to focus on the most important factors and prevent from wasting time and resource. Several techniques have been developed to identify the most critical criterion. The IFS-ANP method, an unbeatable combination of IFS and ANP tools, is a powerful technique to obtain the relative importance of the evaluation criteria. This paper employs the IFS-ANP technique to obtain the relative weights of the evaluation criteria considered in the process of modeling the problem and to rank the criteria based on their corresponding weights. The results demonstrate that the criterion "safety" with value of 0.1996 is located in the top of the list of priorities. It is noted that most decisions in the real world are made in a sophisticated environment in which the goals and constraints are partially or totally unknown and ill-defined. Therefore, the decision problem cannot be accurately formulated by a crisp value. The results show that the proposed model has a great potential for obtaining the weight of the criteria under an uncertainty environment.

\section{References}

Abdullah, L.; Najib, L. 2016. Sustainable energy planning decision using the intuitionistic fuzzy analytic hierarchy process: choosing energy technology in Malaysia, International Journal of Sustainable Energy 35(4): 360-377. https://doi.org/10.1080/14786451.2014.907292

Abdullah, L.; Najib, L. 2014. A new type-2 fuzzy set of linguistic variables for the fuzzy analytic hierarchy process, Expert Systems with Applications 41(7): 3297-3305. https://doi.org/10.1016/j.eswa.2013.11.028

Alcantud, J. C. R. 2016. A novel algorithm for fuzzy soft set based decision making from multiobserver input parameter data set, Information Fusion 29: 142-148. https://doi.org/10.1016/j.inffus.2015.08.007

Angelov, P. P. 1997. Optimization in an intuitionistic fuzzy environment, Fuzzy Sets and Systems 86(3): 299-306. https://doi.org/10.1016/S0165-0114(96)00009-7

Atanassov, K. T. 1999. Intuitionistic fuzzy sets: Theory and applications. Springer-Verlag Berlin Heidelberg GmbH. https://doi.org/10.1007/978-3-7908-1870-3

Atanassov, K.; Gargov, G. 1998. Elements of intuitionistic fuzzy logic, Fuzzy Sets and Systems 95: 39-52. https://doi.org/10.1016/S0165-0114(96)00326-0

Azimi, R.; Yazdani-Chamzini, A.; Fouladgar, M. M.; Zavadskas, E. K.; Basiri, M. H. 2011. Ranking the strategies of mining sector through ANP and TOPSIS in a SWOT framework, Journal of Business Economics and Management 12(4): 670-689. https://doi.org/10.3846/16111699.2011.626552

Baer, D. R.; Burrows, P. E.; El-Azab, A. A. 2003. Enhancing coating functionality using nanoscience and nanotechnology, Progress in Organic Coatings 47(3-4): 342-356. https://doi.org/10.1016/S0300-9440(03)00127-9 
Bartos, P. J. M. 2006. NANOCONEX Roadmap-novel materials. Centre for Nanomaterials Applications in Construction, Bilbao, Spain.

Bashiri, M.; Badri, H.; Hejazi, T. H. 2011. Selecting optimum maintenance strategy by fuzzy interactive linear assignment method, Applied Mathematical Modelling 35(1): 152-164. https://doi.org/10.1016/j.apm.2010.05.014

Boran, F. E.; Genç, S.; Kurt, M.; Akay, D. 2009. A multi-criteria intuitionistic fuzzy group decision making for supplier selection with TOPSIS method, Expert Systems with Applications 36(8): 11363-11368.

https://doi.org/10.1016/j.eswa.2009.03.039

Broumi, S.; Smarandache, F. 2014. New operations over interval valued intuitionistic hesitant fuzzy set, Mathematics and Statistics 2(2): 62-71.

https://doi.org/10.13189/ms.2014.020202

Dengfeng, L.; Chuntian, C. 2002. New similarity measures of intuitionistic fuzzy sets and application to pattern recognitions, Pattern Recognition Letters 23(1-3): 221-225. https://doi.org/10.1016/S0167-8655(01)00110-6

Fan, B.; Tsang, E. C. C.; Xu, W.; Yu, J. 2017. Double-quantitative rough fuzzy set based decisions: A logical operations method, Information Sciences 378: 264-281. https://doi.org/10.1016/j.ins.2016.05.035

Fouladgar, M. M.; Yazdani-Chamzini, A.; Zavadskas, E. K.; Moini, S. H. H. 2012. A new hybrid model for evaluating the working strategies: case study of construction company, Technological and Economic Development of Economy 18(1): 164-188. https://doi.org/10.3846/20294913.2012.667270

Freedonia. 2012. World nanomaterials, industry study with forecasts for 2016 \& 2021. The Freedonia Group [online], [cited 10 May 2017]. Available from Internet: http://www.freedoniagroup.com

GhorshiNezhad, M. R.; Zolfani, S. H.; Moztarzadeh, F.; Zavadskas, E. K.; Bahrami, M. 2015. Planning the priority of high tech industries based on SWARA-WASPAS methodology: The case of the nanotechnology industry in Iran, Economic Research-Ekonomska Istraživanja 28(1): 11111137. https://doi.org/10.1080/1331677X.2015.1102404

Global Construction Perspectives and Oxford Economics. 2015. Global construction 2030: a global forecast for the construction industry to 2030. Global Construction Perspectives Limited and Oxford Economics Limited.

Gonçalves, H. M.; Lourenço, T. F.; Silva, G. M. 2016. Green buying behavior and the theory of consumption values: A fuzzy-set approach, Journal of Business Research 69(4): 1484-1491. https://doi.org/10.1016/j.jbusres.2015.10.129

Kar, A. K. 2015. A hybrid group decision support system for supplier selection using analytic hierarchy process, fuzzy set theory and neural network, Journal of Computational Science 6: 23-33.

https://doi.org/10.1016/j.jocs.2014.11.002

Keleş, Y. 2009. ObservatoryNano: Economical assessment / Construction sector. Final report. Bax \& Willems Consulting Venturing.

Li, D. F. 2005. Multiattribute decision making models and methods using intuitionistic fuzzy sets, Journal of Computer and System Sciences 70(1): 73-85. https://doi.org/10.1016/j.jcss.2004.06.002

Li, D. F. 2010. A ratio ranking method of triangular intuitionistic fuzzy numbers and its application to MADM problems, Computers \& Mathematics with Applications 60(6): 1557-1570. https://doi.org/10.1016/j.camwa.2010.06.039

Li, D. F. 2014. Decision and Game theory in management with intuitionistic fuzzy sets, in Studies in fuzziness and soft computing. Springer-Verlag Berlin Heidelberg. https://doi.org/10.1007/978-3-642-40712-3
Lin, L.; Yuan, X. H.; Xia, Z. Q. 2007. Multicriteria fuzzy decision-making methods based on intuitionistic fuzzy sets, Journal of Computer and System Sciences 73: 84-88. https://doi.org/10.1016/j.jcss.2006.03.004

Liu, H. W.; Wang, G. J. 2007. Multi-criteria decision-making methods based on intuitionistic fuzzy sets, European Journal of Operational Research 179: 220-233.

https://doi.org/10.1016/j.ejor.2006.04.009

Onat, N. C.; Gumus, S.; Kucukvar, M.; Tatari, O. 2016. Application of the TOPSIS and intuitionistic fuzzy set approaches for ranking the life cycle sustainability performance of alternative vehicle technologies, Sustainable Production and Consumption 6: 12-25. https://doi.org/10.1016/j.spc.2015.12.003

Pask, F.; Lake, P.; Yang, A.; Tokos, H.; Sadhukhan, J. 2017. Sustainability indicators for industrial ovens and assessment using Fuzzy set theory and Monte Carlo simulation, Journal of Cleaner Production 140(3): 1217-1225. https://doi.org/10.1016/j.jclepro.2016.10.038

Rabbani, A.; Zamani, M.; Yazdani-Chamzini, A.; Zavadskas, E. K. 2014. Proposing a new integrated model based on sustainability balanced scorecard (SBSC) and MCDM approaches by using linguistic variables for the performance evaluation of oil producing companies, Expert Systems with Applications 41: 7316-7327. https://doi.org/10.1016/j.eswa.2014.05.023

Saafi, M.; Romine, P. 2005. Nano- and microtechnology, Concrete International 27(12): 28-34.

Saaty, T. L. 1980. The Analytic Hierarchy Process. McGrawHill, New York.

Saaty, T. L. 1996. Decision making for Leaders. RWS Publications, Pittsburgh

Shariati, S.; Yazdani-Chamzini, A.; Salsani, A.; Tamosaitiene, J. 2014. Proposing a new model for waste dump site selection: Case study of Ayerma Phosphate Mine, Inzinerine Ekonomika-Engineering Economics 25(4): 410419. https://doi.org/10.5755/j01.ee.25.4.6262

Shu, M. H.; Cheng, C. H.; Chang, J. R. 2006. Using intuitionistic fuzzy sets for fault-tree analysis on printed circuit board assembly, Microelectronics Reliability 46(12): 2139-2148. https://doi.org/10.1016/j.microrel.2006.01.007

Skarmeas, D.; Leonidou, C. N.; Saridakis, Ch. 2014. Examining the role of CSR skepticism using fuzzy-set qualitative comparative analysis, Journal of Business Research 67(9): 1796-1805. https://doi.org/10.1016/j.jbusres.2013.12.010

Sun, B.; Ma, W.; Qian, Y. 2017. Multigranulation fuzzy rough set over two universes and its application to decision making, Knowledge-Based Systems, In Press. https://doi.org/10.1016/j.knosys.2017.01.036

Sun, B.; Ma, W.; Zhao, H. 2014. Decision-theoretic rough fuzzy set model and application, Information Sciences 283(1): 180-196. https://doi.org/10.1016/j.ins.2014.06.045

Szmidt, E.; Kacprzyk, J. 2001. Entropy for intuitionistic fuzzy sets, Fuzzy Sets and Systems 118: 467-477. https://doi.org/10.1016/S0165-0114(98)00402-3

$\mathrm{Xu}, \mathrm{Z}$;; Zhao, N. 2016. Information fusion for intuitionistic fuzzy decision making: An overview, Information Fusion 28: 10-23. https://doi.org/10.1016/j.inffus.2015.07.001

Yazdani-Chamzini, A. 2014a. An integrated fuzzy multi criteria group decision making model for handling equipment selection, Journal of Civil Engineering and Management 20(5): 660-673.

https://doi.org/10.3846/13923730.2013.802714

Yazdani-Chamzini, A. 2014b. Proposing a new methodology based on fuzzy logic for tunnelling risk assessment, Journal of Civil Engineering and Management 20(1): 82-94. https://doi.org/10.3846/13923730.2013.843583

Zadeh, L. A. 1965. Fuzzy set, Information and Control 8: 338353. https://doi.org/10.1016/S0019-9958(65)90241-X 
Zhu, W.; Gibbs, J. C.; Bartos, P. J. M. 2004. Application of nanotechnology in construction-current status and future potential, in Proceeding of the $1^{\text {st }}$ International Symposium on Nanotechnology in Construction, 23-25 June 2003, University of Paisley, Paisley, Scotland, 31-46. https://doi. org/10.1039/9781847551528-00031

Shahram SHARIATI. PhD, Assist. Prof. at the Department of Architecture, Sari branch, Islamic Azad University, Sari, Iran. He is chief of Ayerma international industrial and mining research Co. He is graduated from science and research branch, Islamic Azad University, Tehran-Iran. He is author of more than 37 research papers. His research interests comprise architecture, decision making, fuzzy logic, geology, modeling, and optimization.

Masoumeh ABEDI. MSc student in Department of Architecture, Islamic Azad University, Sari branch, Sari, Iran. She has more than 5 research papers. His research interests include architecture, building design, decision making, and modeling.

Alieh SAEDI. PhD candidate in Mineral Processing. She graduated from Imam Khomeini International University, Qazvin, Iran. Her interests include decision support systems, mineral processing, material selection, and modeling.

Alieh SAEDI. PhD candidate in Mineral Processing. She graduated from Imam Khomeini International University, Qazvin, Iran. Her interests include decision support systems, mineral processing, material selection, and modeling.

Abdolreza YAZDANI-CHAMZINI. PhD student in mining engineering, Tarbiat Modares University, Tehran-Iran. Author of more than 60 research papers. In 2011 he graduated from the Science and Engineering Faculty at Tarbiat Modares University, Tehran-Iran. His research interests include decision making, forecasting, modeling, fuzzy logic, and optimization.

Jolanta TAMOŠAITIENĖ. PhD, Vice-Dean of Civil Engineering Faculty and Assoc. Prof. at the Dept. of Construction Technology and Management, Vilnius Gediminas Technical University, Lithuania. She is the member of EURO Working Group „OR in Sustainable Development and Civil Engineering“. She has published 26 scientific papers. Research interests: construction technology and organisation, construction project administration, decision-making and grey theory.

Jonas ŠAPARAUSKAS. Doctor, Associated Professor at the Department of Construction Technology and Management, Vice-Dean of Undergraduate Studies at the Faculty of Civil Engineering at Vilnius Gediminas Technical University. He is a member of the EURO Working Group OR in Sustainable Development and Civil Engineering (EWG-ORSDCE). He has published over 50 papers. Research interests: construction technology and organisation, project management, quality management, multiple criteria decision making, sustainable development.

Stanislav STUPAK. PhD in Structural Engineering, Assoc. Prof. and the Head of the Department of Strength of Materials and Engineering Mechanics from the Vilnius Gediminas Technical University, Vilnius, Lithuania. He has published over 35 papers. His research interests include mechanics of structures and materials, modeling, optimization, and fracture mechanics. 